\title{
Graphitized biogas-derived carbon nanofibers as anodes
}

\author{
for lithium-ion batteries
}

\author{
Nuria Cuesta, Ignacio Cameán*, Alberto Ramos, Ana B. García
}

Instituto Nacional del Carbón, CSIC, Francisco Pintado Fe 26, 33011 Oviedo, Spain

\begin{abstract}
The electrochemical performance as potential anodes for lithium-ion batteries of graphitized biogas-derived carbon nanofibers (BCNFs) is investigated by galvanostatic cycling versus $\mathrm{Li} / \mathrm{Li}^{+}$at different electrical current densities. These graphitic nanomaterials have been prepared by high temperature treatment of carbon nanofibers produced in the catalytic decomposition of biogas. At low current density, they deliver specific capacities comparable to that of oil-derived micrometric graphite, the capacity retention values being mostly in the range $70-80$ $\%$ and cycling efficiency $\sim 100 \%$. A clear tendency of the anode capacity to increase alongside the BCNFs crystal thickness was observed. Besides the degree of graphitic tri-dimensional structural order, the presence of loops between the adjacent edges planes on the graphene layers, the mesopore volume and the active surface area of the graphitized BCNFs were found to influence on battery reversible capacity, capacity retention along cycling and irreversible capacity. Furthermore, provided that the development of the crystalline structure is comparable, the graphitized BCNFs studied show better electrochemical rate performance than micrometric graphite. Therefore, this result can be associated with the nanometric particle size as well as the larger surface area of the BCNFs which, respectively, reduces the diffusion time of the lithium ions for the intercalation/de-intercalation processes, i.e. faster charge-discharge rate, and increases the contact area at the anode active material/electrolyte interface which may improve the $\mathrm{Li}^{+}$ions access, i.e. charge transfer reaction.
\end{abstract}

Keywords: Biogas, Carbon nanofibers, Graphitic nanomaterials, Anodes, Lithiumion batteries

* Corresponding author. Tel.: +34 985119090

E-mail address: icamean@incar.csic.es (I. Cameán) 


\section{Introduction}

Political, scientific and social sectors of modern society agree about the need for reducing the widespread use of fossil fuels as energy resources which has made the global economy fully-dependent on them. This approach is the result of the growing concern about the non-renewable nature of these resources with inevitably end reserves and the environmental pollution associated with their utilization. To tackle the challenge of decreasing the dependency on fossil fuels, the attention has been focused on the exploitation of renewable energy sources for electricity generation and the implementation of the electric vehicle (EV), which require of highly-efficient electrical energy storage/supply (EES) systems [1]. Among them, lithium-ion batteries (LIBs), which are the energy source for most of the mobile electronic devices (laptops, smartphones, tablets, etc.), with a global market value of 17.6 billons $\$$ USA in 2013 [2], are being used in some stationary large scale EES systems from wind and solar energies which are extremely discontinuous and stochastic [3]. Moreover, LIBs have been scaled-up for powering EVs. In this context, the development of long-life, environmentally friendly, low-cost, high-power and high-energy density LIBs to meet the needs of these applications (e.g., more autonomy and faster recharges for EVs) is a subject of great interest for the scientists in the $21^{\text {st }}$ century [4].

Given that the overall performance of LIBs is largely governed by the electrode active materials, the development of new ones, particularly nanomaterials to replace those of micrometer size, which are currently used, is receiving significant attention by the researchers [5]. The main advantages of nanomaterials over micrometer-sized materials are associated with the reduction of the solid-phase 
diffusion time of the lithium ions $\left(\mathrm{Li}^{+}\right)$, thus allowing faster intercalation/deintercalation processes, i.e. faster charge-discharge rate, and the increase of the area at electrode/electrolyte interface which may improve the $\mathrm{Li}^{+}$access (charge transfer reaction) [6]. As a result of these two effects, both the power and the energy of the battery would be improved.

Focusing on the anode, graphite is nowadays the active material of choice par excellence in commercial LIBs. This fact is due to economical (easily accessible and low cost) and operational (relatively high capacity/energy density, long cycle life and low $\mathrm{Li}^{+}$intercalation/de-intercalation potential) reasons, particularly, in comparison with other non-carbon materials [7]. However, the anode of graphite shows relatively low charge rate which limits the battery power density. To overcome this drawback, different types of nanomaterials [8], including nanocarbons such as carbon nanotubes (CNTs), carbon nanofibers (CNFs), graphene, etc. [9] have been investigated as anodes for LIBs. Among them, CNFs, specifically graphitized CNFs, have been successfully tested [10-16]. The graphitization process of CNFs by heating at high temperature (HTT), under inert atmosphere, involves the increase of the graphitic tri-dimensional order and the electrical conductivity accompanied by a decrease of the porosity and the surface area $[17,18]$. This fine-tuning of the structure and properties of the CNFs was in line with an improvement of the electrochemical performance as anodes on LIBs [17]. In this respect, graphitized stacked-cup CNFs and graphitized methanederived CNFs that were prepared in our research group by HTT [19], were further investigated for this application [18, 20]. These nanomaterials showed good performance in terms of specific capacity, capacity retention along cycling and 
cycling efficiency, even outperforming synthetic graphite having micrometric particle size, particularly as regards battery charge-discharge rate.

Based on these precedent results, it can be concluded that graphitized hydrocarbon-derived CNFs might be valuable nanomaterials to be used in LIBs. However, it is important to consider that, like graphite (whose main precursor is petroleum coke), they have been obtained from non-renewable energy sources. In an attempt to find an ideal anodic material from the points of view of efficiency and source, graphitized biogas-derived carbon nanofibers (BCNFs) are herein considered, for the first time. Biogas is a renewable energy source which is currently used in co-generation combustion plants for the production of heat and electricity. Nevertheless, the exploitation of biogas for different applications seems to be an interesting option (i.e. the catalytic decomposition of biogas to simultaneously produce syngas and BCNFs [21]), particularly when considering its renewable origin.

In this work, the electrochemical performance as potential anodes for LIBs of graphitized BCNFs was investigated by galvanostatic cycling versus $\mathrm{Li}^{\prime} \mathrm{Li}^{+}$at different electrical current densities. These graphitic nanomaterials have been prepared by HTT of BCNFs produced in the catalytic decomposition of biogas as reported previously $[\mathbf{2 1}, \mathbf{2 2}]$. The anodic behavior of different graphitized BCNFs is discussed in terms of battery reversible capacity, irreversible capacity in the first cycle, retention of capacity along cycling and cycle efficiency by considering the influence of structural (graphitic order as evaluated from XRD parameters) and textural (surface area, pore volume) properties. The mechanism of $\mathrm{Li}^{+}$ion intercalation/de-intercalation into/from these novel nanomaterials is also analyzed. 


\section{Materials and methods}

\subsection{Graphitized BCNFs: source and preparation}

Five different BCNFs from the catalytic decomposition of biogas were heat treated in the temperature interval of $2600-2800{ }^{\circ} \mathrm{C}$ for $1 \mathrm{~h}$ in argon flow, by using a graphite electrical furnace. The graphitized BCNFs (25 in total) thus prepared were named by adding a suffix with the temperature in the BCNFs precursor designation (e.g. BCNF1-6), such as BCNF1-6/2600. The experimental set up and BCNFs characteristics can be found in [22]. Furthermore, a description of the production and composition of the BCNFs that are used in this work as precursors is provided (see Table S1 in the Electronic Supporting Information). For simplicity, the original graphitized BCNFs designation (e. g. BCNF1-6/2600) has been abbreviated in this paper (e.g. BCNF16/26).

\subsection{Characterization techniques}

The interlayer spacing, $d_{002}$, and the mean crystallite sizes along $a, L_{a}$, and $c$, $L_{c}$, axes are used to evaluate the degree of structural order of the graphitized BCNFs [23]. They were calculated from the X-ray diffractograms which were recorded in a Bruker D8 powder diffractometer as described elsewhere [24]. The $d_{002}$ was determined from the position of the (002) peak by applying Bragg's equation while the $L_{c}$ and $L_{a}$ were calculated from (002) and (110) peaks, respectively, using the Scherrer formula, with values of $\mathrm{K}=0.9$ for $L_{c}$ and $\mathrm{K}=1.84$ for $L_{a}$ [25]. Typical standard errors of the XRD parameters are $<3 \%$ and $<5 \%$ of 
the reported values for $L_{c}$ and $L_{a}$, respectively; the interlayer spacing values are more precise, with standard errors of $<0.06 \%$.

The textural properties of the graphitized BCNFs were measured by $\mathrm{N}_{2}$ adsorption-desorption at $-196{ }^{\circ} \mathrm{C}$ in a Micromeritics ASAP 2420 volumetric adsorption system. Before measurements, the samples were degassed overnight at $250{ }^{\circ} \mathrm{C}$. The specific surface areas $\left(\mathrm{S}_{\mathrm{BET}}\right)$ were calculated by applying the Brunauer-Emmett-Teller (BET) method, taking $16.2 \mathrm{~nm}^{2}$ for the cross-sectional area of the nitrogen-adsorbed molecule. Total pore volumes $\left(V_{t}\right)$ were determined by the amount of $\mathrm{N}_{2}$ adsorbed at $\mathrm{p} / \mathrm{p}^{0}=0.97$. Mesopore volumes $(2-50 \mathrm{~nm})$ were calculated from the cumulative pore size distributions obtained by applying the DFT (Density Functional Theory) method to the $N_{2}$ adsorption isotherms $\left(p / p^{0}=\right.$ 0.97).

For comparison purposes, a synthetic graphite (SG) with micrometric particle size that is currently commercialized for anode in LIBs was also characterized by these techniques.

\subsection{Cell preparation and electrochemical measurements}

To carry out the electrochemical study of the graphitized BNCFs and SG graphite of reference, two-electrode (working + counter) Swagelok-type laboratory cells were used. To prepare the working electrode, firstly the graphitized BCNFs (active material, $80 \mathrm{wt} . \%$ ) and the polyvinylidene fluoride (PVDF) binder (20 wt.\%) were mixed in 1-methyl-2-pirrolidone (NMP) solution. The slurry was dried at $60{ }^{\circ} \mathrm{C}$ for $24 \mathrm{~h}$. Afterwards, a small amount of this composite (active material + binder) was deposited onto a copper disc (12 $\mathrm{mm}$ of diameter and $25 \mu \mathrm{m}$ of thickness) 
and a few drops of NMP were added. Then it was dried at $120^{\circ} \mathrm{C}$ under vacuum for at least 2 h. Finally, it was pressed twice with a hydraulic press at $45 \mathrm{MPa}$ to obtain the working electrode. The electrode load (active material + binder) was calculated by weight difference, being in the range $3.5-14.5 \mathrm{mg} \mathrm{cm}^{-2}$. A metallic lithium disc of $12 \mathrm{~mm}$ of diameter was used as counter electrode. The assembly of the cell was carried out in a dry box with $\mathrm{O}_{2}$ and $\mathrm{H}_{2} \mathrm{O}$ contents below 0.1 ppm. The electrodes were separated by two micro-fiber glass discs impregnated with a few drops of the electrolyte solution, $1 \mathrm{M} \mathrm{LiPF}_{6}$ in ethylene carbonate $(\mathrm{EC})$ :diethyl carbonate (DEC), 1:1, w:w.

The electrochemical measurements of the cells were conducted in a Biologic multichannel VMP2/Z potentiostat/galvanostat. The galvanostatic cycling of the all working electrodes was performed in the 2.1-0.003 $\mathrm{V}$ potential range $v s \mathrm{Li} / \mathrm{Li}^{+}$at a constant current density of $37.2 \mathrm{~mA} \mathrm{~g}^{-1}(\mathrm{C} / 10)$ for 50 cycles, or variable $\left(93 \mathrm{~mA} \mathrm{~g}^{-1}\right.$, $186 \mathrm{~mA} \mathrm{~g}^{-1}, 372 \mathrm{~mA} \mathrm{~g}^{-1}$ and $744 \mathrm{~mA} \mathrm{~g}^{-1}$, i.e. $\mathrm{C} / 4, \mathrm{C} / 2,1 \mathrm{C}$, and $2 \mathrm{C}$ rates) 10 cycles at each current density, starting and finishing at the lowest one).

\section{Results and discussion}

\section{1. $\mathrm{Li}^{+}$ion intercalation/de-intercalation mechanism}

The potential vs $\mathrm{Li} / \mathrm{Li}^{+}$against discharge-charge capacity plots (potential profiles) of the graphitized BCNFs are typical of graphite-like materials, thus exhibiting different plateau regions [26]. As an example, Fig. 1a-c shows the potential curves of BCNF27*/26, BCNF27*1/28 and BCNF27*7/28 for cycles 1,2 , 
10 and 50. During the first discharge, the potential vs $\mathrm{Li}^{\prime} / \mathrm{Li}^{+}$drops rapidly until $\sim 0.8$ V. At this potential, a plateau is observed which is assigned to SEI (Solid Electrolyte Interface) formation on the surface of the electrode. This phenomenon occurs in all carbon materials and its extension depends mainly on their surface properties [27]. With further discharging, the potential gradually decreases to $\sim 0.2$ $\mathrm{V}$ at which the lithium intercalation into the graphene layers of the materials starts, as confirmed by the appearance of three plateaux at $\sim 0.18 \mathrm{~V}, \sim 0.09 \mathrm{~V}$ and $\sim 0.06$ $\mathrm{V}$ [28]. These plateaux which are also observed in the corresponding first charge, indicating that $\mathrm{Li}^{+}$ions intercalation is a reversible process, can be better appreciated in the zoom area below $0.2 \mathrm{~V}$ inset in Fig. 1a-c. As expected, no plateaux at $0.8 \mathrm{~V}$ appear in the profiles of this first charge due to the irreversible nature of the SEI formation. Comparable charge-discharge potential profiles are obtained in the following cycles (Fig. 1a-c). However, the length of these plateaux decreases slightly along cycling as can be confirmed by the analysis of the differential charge-discharge capacity against potential $v s{\mathrm{Li} / L \mathrm{Li}^{+}}(<0.5 \mathrm{~V})$ plots in Figure 2a-c, in which the peaks corresponding to the different stages of $\mathrm{Li}^{+}$ions intercalation $(\sim 0.18 \mathrm{~V}, \sim 0.09 \mathrm{~V}, \sim 0.06 \mathrm{~V}$ in the negative axis) and de-intercalation $(0.11 \mathrm{~V}, \sim 0.15 \mathrm{~V}$ and $\sim 0.24 \mathrm{~V}$ in the positive axis) appear. Anyhow, as will be discussed below, this decrease is not of much significance, as shown by the values of the capacity retention along cycling. Furthermore, small charging and discharging cell overpotential with a general trend to slightly increase from cycle 2 to cycle 50 is observed (see Fig. S1 and Table S2 of the Electronic Supporting Information). This fact may be associated with the increase of the charge transfer resistance of the SEI layer [29], thus to some extent explaining the above mentioned capacity loss with cycling. 


\subsection{Galvanostatic cycling at constant electric current density}

The main electrochemical parameters, discharge capacity $\left(C_{\text {disc }}\right)$ in the $1^{\text {st }}$, $2^{\text {nd }}, 50^{\text {th }}$ cycles, irreversible capacity in the $1^{\text {st }}$ cycle $\left(\mathrm{C}_{\text {irr }}\right)$, and capacity retention (R) from the galvanostatic cycling, at a constant electrical current density of 37.2 $\mathrm{mA} \mathrm{g}^{-1}$, of all graphitized BCNFs are summarized in Table 1. Furthermore, to support the discussion of the electrochemical results, the structural (XRD parameters) and textural (surface area) properties of the materials are compiled in Table 2. From a general perspective of this data, it can be concluded that BCNFs having higher degree of graphitic structural order (i. e. larger $L_{c}$ and $L_{a}$ as well as smaller $d_{002}$ ) deliver larger capacity along cycling. In line with this, discharge capacities up to $\sim 320 \mathrm{mAh} \mathrm{g}^{-1}$ and to $\sim 250 \mathrm{mAh} \mathrm{g}^{-1}$ at cycles 2 and 50, respectively, were calculated for $B C N F 27^{\star} 7 / 28\left(L_{c} \sim 48 \mathrm{~nm}\right)$, which compare well with those of $S G$ graphite of reference studied $\left(L_{c} \sim 47 \mathrm{~nm}\right)$, versus values of $\sim$ $230 \mathrm{mAh} \mathrm{g}^{-1}$ and $\sim 165 \mathrm{mAh} \mathrm{g}^{-1}$ for BCNF27 $/ 26\left(L_{c} \sim 6 \mathrm{~nm}\right)$. The dependence of the electrochemical intercalation of lithium ions in graphite-like materials (i. e. anode capacity) on their crystal structure is well known. Specifically, the crystal thickness, $L_{c}$, was reported to be the most influencing structural parameter provided that the morphology and the particle size of the materials are similar [20, 30-35]. In this context, reasonably good linear correlations between $L_{c}$ and capacity were attained in previous works in which the electrochemical performance as anode in LIBs of graphitic materials derived from anthracites [30] and coal combustion wastes [35] was investigated. As regards the graphitized BCNFs studied in this work, a clear tendency of the electrode capacity to increase 
alongside the materials crystal thickness was observed (see Fig. S2 in the Electronic Supporting Information).

Focusing on the irreversible capacity (irreversible consumption of $\mathrm{Li}^{+}$ions due to SEl formation) in the first discharge-charge cycle $\left(C_{\text {irr }}\right)$ in Table 1 , the graphitized BCNFs show values in the range 32-66 \% which are much higher than that of SG graphite (18\%), and unusually large as compared to other micrometric sized graphitic materials that were investigated as anodes for LIBs [24, 30]. $A$ priori, this fact could be associated with the surface area since, as mentioned above, the $\mathrm{C}_{\text {irr }}$ in carbon materials has been reported to depend on this parameter [27]. Thus, by comparing the electrochemical (Table 1) and the structural/textural (Table 2) data of the materials studied, it is evident that the irreversible capacity of the graphitized BCNFs tends to decrease parallel to the surface area. This tendency can be better appreciated in Fig.3. In the graphitization process, the decrease of the materials porosity (surface area/pore volume) is attributed to the improvement of the structural order as a consequence of the crystal growth and the removal of structural defects. In this context, the smallest values of the surface area (21-35 $\left.\mathrm{m}^{2} \mathrm{~g}^{-1}\right)$ were determined for materials having larger development of the graphite tri-dimensional structure (Table 2). However, even graphitized BCNFs (e.g. BCNF167/28 or BCNF27*7/28) with structural order comparable to SG graphite have higher $\mathrm{S}_{\mathrm{BET}}$ (21 or $36 \mathrm{~m}^{2} \mathrm{~g}^{-1}$ vs $5 \mathrm{~m}^{2} \mathrm{~g}^{-1}$ for SG graphite) because of their nanometric particle size. Furthermore, the called active surface area (ASA) has been reported to be directly proportional to the irreversible lithium consumption at the negative carbon electrode during the first charge [36]. On a graphite surface, the edge planes as well as the crystal structural imperfections including vacancies and dislocations are responsible for the active sites [37]. 
Considering that the loops (and multi-loops), which are typically formed between adjacent active graphene edges planes during the graphitization thermal treatment of carbon nanofibers [17], are dislocations, they are expected to influence on the extent of the irreversible capacity. In this context, the presence of loops in the graphitized BCNFs investigated herein as anodes for LIBs has been noticed in a previous work [22], thus contributing to the higher $\mathrm{C}_{\text {irr }}$ of these nanofilaments as compared to SG graphite (Table 1).

Other important parameter which is basic to evaluate the performance as anode in lithium-ion batteries of any material is the cyclability, i.e., capacity retention $(\mathrm{R})$ along the cycling after the SEl formation. The graphitized BCNFs show good-to-excellent cyclability with $\mathrm{R}$ values mostly in the range $70-80 \%$ after 50 cycles (Table 1) and cycling efficiency ([charge capacity/discharge capacity]x100) $100 \%$. In general, as it was concluded for the discharge capacity, those more structurally ordered graphitized BCNFs lead to better capacity retentions (Table 1). However, the presence of mesopores, which is typical in these carbon nanofilaments [17], also appears to influence on this electrochemical parameter because they might increase the probability of inserting solvated lithium ions and consequently, resulting in structural damage. As an example, the galvanostatic plots (specific capacity vs cycle number) of two graphitized BCNFs series are presented in Fig. 4. An improvement of the cycling performance of these nanomaterials in terms of specific reversible capacity and capacity retention along cycling is clearly observed by increasing the degree of structural order within the same series (Table 2). However, materials from different series and similar development of the tri-dimensional graphitic structure, such as BCNF177/28 $\left(L_{c} \sim 47 \mathrm{~nm}\right)$ and BCNF27*7/28 $\left(L_{c} \sim 48 \mathrm{~nm}\right)$, show some differences 
as regards the capacity retention value (81\% vs $77 \%)$. Provided that lithium ion intercalation into all of these materials is basically reversible (100\% cycling efficiency), the lower $\mathrm{R}$ value of $\mathrm{BCNF} 27^{\star} 7 / 28$ may be explained on the basis of its larger mesopore volume $\left(0.107 \mathrm{~cm}^{3} \mathrm{~g}^{-1}\right.$ vs $0.080 \mathrm{~cm}^{3} \mathrm{~g}^{-1}$ for $\left.\mathrm{BCNF} 177 / 28\right)$. This effect is more noticeable by comparing the cycling performance of BCNF171/28 (R $=79 \%)$ and BCNF27*1/28 $(\mathrm{R}=68 \%)$ with mesopore volumes of 0.105 and 0.293 $\mathrm{cm}^{3} \mathrm{~g}^{-1}$, respectively. As a result of the larger mesopore volume and surface area (Table 2) which, as mentioned, increase the irreversible consumption of lithium during the first cycle, lower specific reversible capacity was delivered at the end of cycling by BCNF27*1/28 with higher degree of structural order $\left(L_{c} \sim 21 \mathrm{~nm}\right)$ as compared to BCNF171/28 ( $\left.L_{c} \sim 9 \mathrm{~nm}\right)$. Furthermore, higher overpotential, increasing along cycling, which may be associated with the increase of the charge transfer resistance of the SEI layer [29] and therefore affecting the capacity, was calculated for BCNF27*1/28 (see Fig. S1 and Table S2 of the Electronic Supporting Information).

Finally, the influence of the loops, which as mentioned above were found in the graphitized BCNFs studied [22], on the specific capacity provided by these nanomaterials cannot be discarded since, attending the values of the crystal thickness, more differences among them should be expected (i.e., BCNF16/26 and BCNNF167/28 with $L_{c}$ values of $\sim 11$ and $\sim 35 \mathrm{~nm}$ deliver discharged capacities at the end of cycling of 234 and $258 \mathrm{~mA} \mathrm{~h} \mathrm{~g}^{-1}$, Tables 1-2). The loops in the carbon nanofibers have been suggested to hamper the intercalation of the lithium ions into all of the graphene layers available, thus decreasing the specific capacity [15]. 


\subsection{Effect of electrical current density on galvanostatic cycling}

The cycling behavior of $\mathrm{BCNF} 177 / 28$ and $\mathrm{BCNF} 27^{\star} 7 / 28$ electrodes at increasing electrical current density $\left(93 \mathrm{~mA} \mathrm{~g}^{-1}, 186 \mathrm{~mA} \mathrm{~g}^{-1}, 372 \mathrm{~mA} \mathrm{~g}^{-1}\right.$ and 744 $\mathrm{mA} \mathrm{g}^{-1}$, i.e. $\mathrm{C} / 4, \mathrm{C} / 2,1 \mathrm{C}$ and $2 \mathrm{C}$ rates) is depicted in Fig. 5 . Among the different graphitized BCNFs, they were selected because they showed good electrochemical performance at the lowest electrical current density of $37.2 \mathrm{~mA} \mathrm{~g}^{-1}$ (Table 1, Fig. 4). First of all, it should be remarked that the capacity values provide by these nanomaterials at any current density are higher than that of SG graphite of reference, whose electrochemical results are also included in Fig. 5. As an example, discharge capacity values of $\sim 240, \sim 176$ and $\sim 91 \mathrm{mAh} \mathrm{g}^{-1}$ were calculated for $\mathrm{BCNF} 27^{\star} 7 / 28, \mathrm{BCNF} 177 / 28$ and $\mathrm{SG}$, respectively, after cycling at $186 \mathrm{~mA} \mathrm{~g}^{-1}$. Moreover, as can be seen by comparing the electrochemical results in Table 1 and those appearing in Fig. 5, these graphitized BCNFs are able to basically retain the whole cell capacity on increasing two half times the current density (from the lowest $37.2 \mathrm{~mA} \mathrm{~g}^{-1}$ to $93 \mathrm{~mA} \mathrm{~g}^{-1}$ ). A further increase of the current density up to $186 \mathrm{~mA} \mathrm{~g}^{-1}$ has moderate repercussion on the specific capacity delivered by both BCNF27*7/28 and BCNF177/28. Thus, discharge capacity losses in the range of $\sim 50 \mathrm{mAh} \mathrm{g}^{-1}$ were detected. Even at the current density of $372 \mathrm{~mA} \mathrm{~g}^{-1}$ (1C rate which is usually required for consumer electronic applications), these nanomaterials still provide specific capacities over $100 \mathrm{mAh} \mathrm{g}^{-}$ 1. Furthermore, the initial specific capacity at $93 \mathrm{~mA} \mathrm{~g}^{-1}$ is mostly recovered when returning to this cycling current from $744 \mathrm{~mA} \mathrm{~g}^{-1}$ (Fig. 4). In contrast, the SG graphite electrode shows higher sensitiveness to the increase of this electrical parameter and thus, larger capacity losses were observed during cycling (Fig. 5). 
Consequently, the specific capacity delivered by this electrode falls below $50 \mathrm{mAh}$ $\mathrm{g}^{-1}$ at this $1 \mathrm{C}$ rate. Moreover, the graphitized BCNFs exhibit stable capacity in the whole range of current densities studied, even after cycling back to the initial one ( $R$ values of $\sim 88 \%, 96 \%, 71 \%, 76 \%$ and $93 \%$ were calculated for BCNF27 $7 / 28$ at $\mathrm{C} / 4, \mathrm{C} / 2, \mathrm{C}, 2 \mathrm{C}$ and $\mathrm{C} / 4$, respectively).

\section{Conclusions}

At low electrical current density ( $\mathrm{C} / 10$ charge-discharge rate), the graphitized biogas-derived carbon nanofibers (BCNFs) can provide specific capacities comparable to that of oil-derived graphite of reference, which is commercialized for anodes of LIBs, the capacity retention values being mostly in the range $70-80 \%$ and the cycling efficiency $\sim 100 \%$. However, the use of these nanomaterials leads to higher irreversible capacities as compared to micrometric sized graphitic materials because of their higher surface area. A clear tendency of the anode capacity to increase alongside the BCNFs crystal thickness was observed. Besides the degree of graphitic tri-dimensional structural order, the presence of loops between the adjacent edges planes on the graphene layers, the mesopore volume and the active surface area of the graphitized BCNFs were found to influence on battery reversible capacity, capacity retention along cycling and irreversible capacity.

Provided comparable development of the crystalline structure, the graphitized BCNFs studied show better electrochemical rate performance than micrometric graphite. Therefore, this result can be associated with the nanometric 
particle size as well as the larger surface area of the BCNFs which, respectively, reduces the diffusion time of the lithium ions for the intercalation/de-intercalation processes, i.e. faster charge-discharge rate, and increases the contact area at the anode active material/electrolyte interface which may improve the $\mathrm{Li}^{+}$ions access, i.e. charge transfer reaction.

\section{Acknowledgements}

Financial support from the Spanish Ministry of Economy and Competitiveness (MINECO) under Projects ENE2011-28318-CO3-02 and ENE2014-52189-C2-2-R is gratefully acknowledged. A. Ramos and N. Cuesta, respectively, thank the Spanish Research Council for Scientific Research (CSIC) for a JAE-Doc contract, co-funded by the European Social Fund (ESF), and the MINECO for a Ph.D. grant (BES-2012-052711) to develop the work. Thanks are also given to I. Suelves, J. L. Pinilla and S. de Llobet of the ICB (CSIC) for providing the as-produced BCNFs.

\section{REFERENCES}

[1] N. Armaroli, V. Balzani, Towards an electricity-powered world, Energy Environ. Sci., 4 (2011) 3193-3222.

[2] V. Sapru, Frost \& Sullivan, Analysis of the global lithium-ion battery market: growth opportunities and market outlook, in: F. Sullivan (Ed.) http://www.frost.com/, LONDON - June, 2014.

[3] Office of electricity delivery and energy reliability - United States Department of Energy (DOE), Global energy storage database, www.energy.gov, 2016. 
[4] J. Warner, Chapter 15 - Lithium-ion battery applications, The handbook of lithium-ion battery pack design, Elsevier, Amsterdam, 2015, pp. 177-209.

[5] N.S. Hudak, 4 - Nanostructured electrode materials for lithium-ion batteries A2 - Pistoia, Gianfranco, Lithium-ion batteries, Elsevier, Amsterdam, 2014, pp. $57-82$.

[6] P.G. Bruce, B. Scrosati, J.M. Tarascon, Nanomaterials for rechargeable lithium batteries, Angew. Chem. Int. Ed. (English), 47 (2008) 2930-2946.

[7] B. Scrosati, Recent advances in lithium ion battery materials, Electrochim. Acta, 45 (2000) 2461-2466.

[8] S. Goriparti, E. Miele, F. De Angelis, E. Di Fabrizio, R. Proietti Zaccaria, C. Capiglia, Review on recent progress of nanostructured anode materials for Li-ion batteries, J. Power Sources, 257 (2014) 421-443.

[9] I. Lahiri, W. Choi, Carbon nanostructures in lithium ion batteries: past, present, and future, Crit. Rev. Solid State Mater. Sci., 38 (2013) 128-166.

[10] R. Lawrence, J. Gnanaraj, X. Geng, J. Liang, Carbon nanofibers as effective, low cost replacements for carbon nanotubes in high performance lithium-ion batteries, Science of Advanced Materials, 4 (2012) 877-880.

[11] D. Deng, J.Y. Lee, One-step synthesis of polycrystalline carbon nanofibers with periodic dome-shaped interiors and their reversible lithium-ion storage properties, Chem. Mater., 19 (2007) 4198-4204.

[12] D. Burton, P. Lake, G.G. Tibbetts, M.L. Lake, Novel applications of carbon nanofibers, SAMPE J., 43 (2007) 36-40.

[13] G. Zou, D. Zhang, C. Dong, H. Li, K. Xiong, L. Fei, Y. Qian, Carbon nanofibers: synthesis, characterization, and electrochemical properties, Carbon, 44 (2006) 828-832. 
[14] V. Subramanian, H. Zhu, B. Wei, High rate reversibility anode materials of lithium batteries from vapor-grown carbon nanofibers, J. Phys. Chem. B, 110 (2006) 7178-7183.

[15] H. Habazaki, M. Kiriu, H. Konno, High rate capability of carbon nanofilaments with platelet structure as anode materials for lithium ion batteries, Electrochem. Commun., 8 (2006) 1275-1279.

[16] Z. Shi, C. Chong, J. Wang, C. Wang, X. Yu, Electrospun pitch/polyacrylonitrile composite carbon nanofibers as high performance anodes for lithium-ion batteries, Mater. Lett., 159 (2015) 341-344.

[17] A. Ramos, I. Cameán, A.B. García, Graphitization thermal treatment of carbon nanofibers, Carbon, 59 (2013) 2-32.

[18] A. Ramos, I. Cameán, N. Cuesta, A.B. García, Graphitized stacked-cup carbon nanofibers as anode materials for lithium-ion batteries, Electrochim. Acta, 146 (2014) 769-775.

[19] A.B. Garcia, I. Cameán, I. Suelves, J.L. Pinilla, M.J. Lázaro, J.M. Palacios, R. Moliner, The graphitization of carbon nanofibers produced by the catalytic decomposition of natural gas, Carbon, 47 (2009) 2563-2570.

[20] I. Cameán, A.B. García, I. Suelves, J.L. Pinilla, M.J. Lázaro, R. Moliner, Graphitized carbon nanofibers for use as anodes in lithium-ion batteries: Importance of textural and structural properties, J. Power Sources, 198 (2012) 303-307.

[21] S. de Llobet, J.L. Pinilla, R. Moliner, I. Suelves, J. Arroyo, F. Moreno, M. Muñoz, C. Monné, I. Cameán, A. Ramos, N. Cuesta, A.B. Garcia, Catalytic decomposition of biogas to produce hydrogen rich fuels for SI engines and valuable nanocarbons, Int. J. Hydrogen Energy, 38 (2013) 15084-15091. 
[22] N. Cuesta, I. Cameán, A. Ramos, S. de Llobet, A.B. García, Graphitic nanomaterials from biogas-derived carbon nanofibers, Fuel Process. Technol., 152 (2016) 1-6.

[23] A. Cuesta, P. Dhamelincourt, J. Laureyns, A. Martinez-Alonso, J. M. D. Tascon, Comparative performance of X-ray diffraction and Raman microprobe techniques for the study of carbon materials, J. Mater. Chem., 8 (1998) 2875-2879.

[24] I. Cameán, A.B. Garcia, Graphite materials prepared by HTT of unburned carbon from coal combustion fly ashes: performance as anodes in lithiumion batteries, J. Power Sources, 196 (2011) 4816-4820.

[25] J. Biscoe, B.E. Warren, An X-Ray study of carbon black, J. Appl. Phys., 13 (1942) 364-371.

[26] K. Guerin, A. Fevrier-Bouvier, S. Flandrois, M. Couzi, B. Simon, P. Biensan, Effect of graphite crystal structure on lithium electrochemical intercalation, J. Electrochem. Soc., 146 (1999) 3660-3665.

[27] M.E. Spahr, H. Buqa, A. Würsig, D. Goers, L. Hardwick, P. Novák, F. Krumeich, J. Dentzer, C. Vix-Guterl, Surface reactivity of graphite materials and their surface passivation during the first electrochemical lithium insertion, J. Power Sources, 153 (2006) 300-311.

[28] Z. Ogumi, M. Inaba, Carbon Anodes, in: W. van Schalkwijk, B. Scrosati (Eds.) Advances in lithium-ion batteries, Springer Science \& Business Media2007, pp. 79-101.

[29] A. Ponrouch, E. Marchante, M. Courty, J.-M. Tarascon, M.R. Palacin, In search of an optimized electrolyte for Na-ion batteries, Energy Environ. Sci., 5 (2012) 8572-8583. 
[30] I. Cameán, P. Lavela, J.L. Tirado, A.B. García, On the electrochemical performance of anthracite-based graphite materials as anodes in lithium-ion batteries, Fuel, 89 (2010) 986-991.

[31] J.C. Arrebola, A. Caballero, L. Hernán, J. Morales, Graphitized carbons of variable morphology and crystallinity: a comparative study of their performance in lithium cells, J. Electrochem. Soc., 156 (2009) A986-A992.

[32] M. Endo, C. Kim, K. Nishimura, T. Fujino, K. Miyashita, Recent development of carbon materials for $\mathrm{Li}$ ion batteries, Carbon, 38 (2000) 183-197.

[33] J. Dahn, A. Sleigh, H. Shi, J. Reimers, Q. Zhong, B. Way, Dependence of the electrochemical intercalation of lithium in carbons on the crystal structure of the carbon, Electrochim. Acta, 38 (1993) 1179-1191.

[34] M. Endo, Y. Nishimura, T. Takahashi, K. Takeuchi, M. Dresselhaus, Lithium storage behavior for various kinds of carbon anodes in $\mathrm{Li}$ ion secondary battery, J. Phys. Chem. Solids, 57 (1996) 725-728.

[35] I. Cameán, A. Ramos, N. Cuesta, A.B. García, Anodic rate performance in lithium-ion batteries of graphite materials based on carbonaceous wastes, J. Electrochem. Soc., 161 (2014) A2026-A2030.

[36] F. Béguin, F. Chevallier, C. Vix-Guterl, S. Saadallah, V. Bertagna, J. Rouzaud, E. Frackowiak, Correlation of the irreversible lithium capacity with the active surface area of modified carbons, Carbon, 43 (2005) 2160-2167.

[37] W.P. Hoffman, F.J. Vastola, P.L. Walker, Chemisorption of alkanes and alkenes on carbon active sites, Carbon, 22 (1984) 585-594. 


\section{TABLES}

\section{Table 1}

Electrochemical parameters from the galvanostatic cycling at $37.2 \mathrm{~mA} \mathrm{~g}^{-1}$ of graphitized BCNFs and SG graphite.

\begin{tabular}{|c|c|c|c|c|c|}
\hline Material & $\begin{array}{c}\mathrm{C}_{\text {disc }} / \mathrm{mAh} \mathrm{gh}^{-1} \\
\left(1^{\text {st }} \text { cycle }\right)\end{array}$ & $\begin{array}{c}\mathrm{C}_{\text {disc }} / \mathrm{mAh} \mathrm{g}^{-1} \\
\left(2^{\text {nd }} \mathrm{cycle}\right)\end{array}$ & $\begin{array}{c}\mathrm{C}_{\text {disd }} / \mathrm{mAh} \mathrm{g}^{-1} \\
\left(50^{\text {th }} \text { cycle }\right)\end{array}$ & $\begin{array}{c}\mathrm{C}_{\text {irr }}(\%)^{\mathrm{a}} \\
\left(1^{\text {st }} \text { cycle }\right)\end{array}$ & $\begin{array}{c}R \\
(\%)^{b}\end{array}$ \\
\hline BCNF16/26 & 462 & 275 & 234 & 38 & 85 \\
\hline BCNF16/28 & 452 & 264 & 224 & 46 & 85 \\
\hline BCNF161/28 & 467 & 263 & 190 & 50 & 72 \\
\hline BCNF165/28 & 419 & 275 & 214 & 38 & 78 \\
\hline BCNF167/28 & 444 & 316 & 258 & 32 & 82 \\
\hline BCNF17/26 & 482 & 214 & 152 & 66 & 71 \\
\hline BCNF17/28 & 454 & 201 & 155 & 64 & 77 \\
\hline BCNF171/28 & 435 & 235 & 187 & 52 & 79 \\
\hline BCNF175/28 & 548 & 302 & 254 & 52 & 84 \\
\hline BCNF177/28 & 510 & 311 & 251 & 46 & 81 \\
\hline BCNF26/26 & 484 & 228 & 181 & 58 & 80 \\
\hline BCNF26/28 & 441 & 235 & 162 & 52 & 69 \\
\hline BCNF261/28 & 464 & 250 & 179 & 53 & 72 \\
\hline BCNF265/28 & 484 & 299 & 231 & 48 & 77 \\
\hline BCNF267/28 & 515 & 292 & 231 & 49 & 79 \\
\hline BCNF27/26 & 505 & 233 & 177 & 62 & 76 \\
\hline BCNF27/28 & 504 & 227 & 144 & 63 & 63 \\
\hline BCNF271/28 & 480 & 227 & 171 & 60 & 75 \\
\hline BCNF275/28 & 546 & 271 & 220 & 57 & 81 \\
\hline BCNF277/28 & 492 & 262 & 209 & 52 & 80 \\
\hline BCNF27*/26 & 567 & 231 & 166 & 66 & 72 \\
\hline BCNF27*/28 & 548 & 234 & 157 & 65 & 67 \\
\hline BCNF27*1/28 & 531 & 228 & 156 & 64 & 68 \\
\hline BCNF27*5/28 & 532 & 294 & 199 & 50 & 68 \\
\hline BCNF27*7/28 & 537 & 321 & 249 & 46 & 77 \\
\hline SG & 317 & 285 & 244 & 18 & 86 \\
\hline
\end{tabular}

${ }^{\mathrm{a}}$ Irreversible capacity $(\%)=\left[\mathrm{C}_{\text {disc }}\left(1^{\text {st }}\right.\right.$ cycle $)-\mathrm{C}_{\text {charge }}\left(1^{\text {st }}\right.$ cycle $\left.)\right] /\left[\mathrm{C}_{\text {disc }}\left(1^{\text {st }} \text { cycle }\right)\right]^{-1} \times 100$

${ }^{\mathrm{b}}$ Capacity retention $(\%)=\left[\mathrm{C}_{\text {disc }}\left(50^{\text {th }}\right.\right.$ cycle $\left.)\right] /\left[\mathrm{C}_{\text {disc }}\left(2^{\text {nd }} \text { cycle }\right)\right]^{-1} \times 100$ 


\section{Table 2}

Interlayer distance $d_{002}$, crystallite sizes $L_{c}$ and $L_{a}$, and surface area $S_{B E T}$ of graphitized BCNFs and SG graphite.

\begin{tabular}{lcrrc}
\hline Material & $\begin{array}{c}d_{002} \\
(\mathrm{~nm})\end{array}$ & $\begin{array}{c}L_{C} \\
(\mathrm{~nm})\end{array}$ & $\begin{array}{c}L_{a} \\
(\mathrm{~nm})\end{array}$ & $\begin{array}{c}S_{B E T} \\
\left(\mathrm{~m}^{2} \mathrm{~g}^{-1}\right)\end{array}$ \\
\hline BCNF16/26 & 0.3399 & 10.5 & 6.9 & 39 \\
BCNF16/28 & 0.3398 & 10.5 & 37.7 & 38 \\
BCNF161/28 & 0.3397 & 10.1 & 39.6 & 44 \\
BCNF165/28 & 0.3372 & 19.8 & 50.3 & 33 \\
BCNF167/28 & 0.3362 & 35.4 & 99.6 & 21 \\
BCNF17/26 & 0.3420 & 6.9 & 27.8 & 57 \\
BCNF17/28 & 0.3417 & 7.2 & 33.8 & 56 \\
BCNF171/28 & 0.3402 & 8.9 & 45.9 & 43 \\
BCNF175/28 & 0.3361 & 40.9 & $>100.0$ & 59 \\
BCNF177/28 & 0.3360 & 46.8 & $>100.0$ & 33 \\
BCNF26/26 & 0.3410 & 9.3 & 25.4 & 52 \\
BCNF26/28 & 0.3407 & 9.8 & 26.5 & 50 \\
BCNF261/28 & 0.3399 & 10.1 & 34.2 & 46 \\
BCNF265/28 & 0.3380 & 14.9 & 51.3 & 41 \\
BCNF267/28 & 0.3370 & 21.6 & 55.9 & 37 \\
BCNF27/26 & 0.3423 & 6.7 & 22.4 & 64 \\
BCNF27/28 & 0.3420 & 7.1 & 26.4 & 60 \\
BCNF271/28 & 0.3402 & 9.3 & 41.0 & 61 \\
BCNF275/28 & 0.3367 & 25.1 & 57.3 & 50 \\
BCNF277/28 & 0.3364 & 31.1 & 62.9 & 45 \\
BCNF27*/26 & 0.3430 & 6.2 & 25.7 & 73 \\
BCNF27*/28 & 0.3428 & 6.4 & 30.6 & 71 \\
BCNF27*1/28 & 0.3374 & 21.1 & 53.1 & 73 \\
BCNF27*5/28 & 0.3363 & 46.2 & 98.0 & 47 \\
BCNF27*7/28 & 0.3363 & 48.3 & $>100.0$ & 36 \\
SG $^{*}$ & 0.3360 & 47.0 & 99.5 & 5 \\
\hline & & & &
\end{tabular}




\section{CAPTIONS FOR FIGURES}

Fig. 1. Potential vs charge-discharge capacity plots (potential profiles) of graphitized BCNFs: (a) BCNF27*/26, (b) BCNF27 ${ }^{\star} 1 / 28$ and (c) BCNF27*7/28 for the $1^{\text {st }}, 2^{\text {nd }}, 10^{\text {th }}$ and $50^{\text {th }}$ cycles at $37.2 \mathrm{~mA} \mathrm{~g}^{-1}$. Inset: Magnification of the area below $0.2 \mathrm{~V}$.

Fig. 2. Differential charge-discharge capacity vs potential plots of graphitized BCNFs: (a) BCNF27*/26, (b) BCNF27*1/28 and (c) BCNF27*7/28 for the $1^{\text {st }}, 2^{\text {nd }}$, $10^{\text {th }}$ and $50^{\text {th }}$ cycles at $37.2 \mathrm{~mA} \mathrm{~g}^{-1}$.

Fig. 3. Surface area, $S_{B E T}$, of the materials vs irreversible capacity, $C_{\text {irr }}(\%)$.

Fig. 4. Galvanostatic cycling $37.2 \mathrm{~mA} \mathrm{~g}^{-1}$ of two graphitized BNCFs series: (a) BCNF17/26, BCNF171/28, BCNF177/28, and (b) BCNF27*/26, BCNF27*1/28, BCNF27*7/28.

Fig. 5. Cycling performance of $B C N F 177 / 28$ and $B C N F 27^{\star} 7 / 28$ nanomaterials, and SG graphite electrodes at different electrical current densities.

Fig. S1. Differential charge-discharge capacity vs potential of BCNF277/28 for the $1^{\text {st }}, 2^{\text {nd }}, 10^{\text {th }}$ and $50^{\text {th }}$ cycles at $37.2 \mathrm{~mA} \mathrm{~g}^{-1}$.

Fig. S2. Discharge capacity at cycle 2 vs crystallite size, $L_{c}$, of the graphitized BCNFs (data from Table 1 and 2). 


\section{FIGURES}
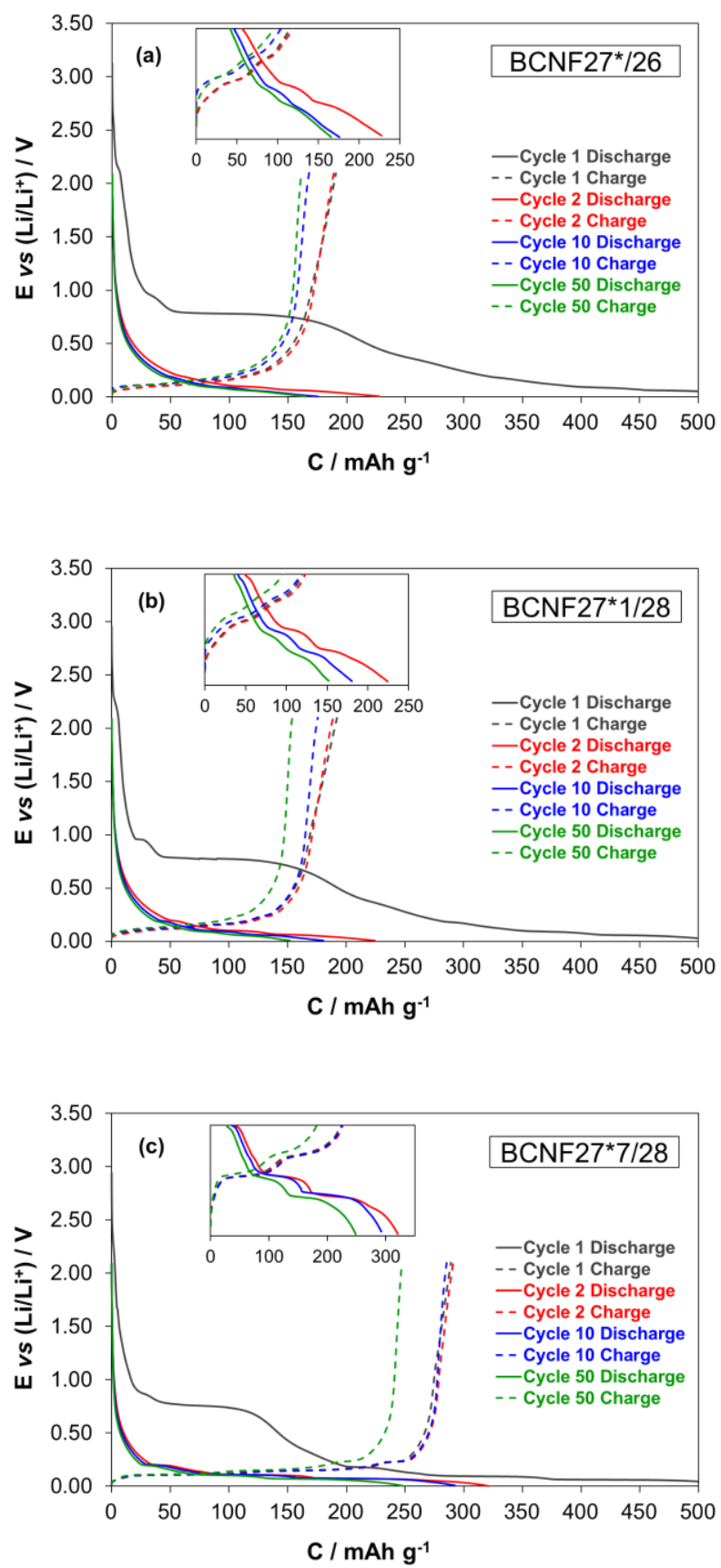

Fig. 1. Potential vs charge-discharge capacity plots (potential profiles) of graphitized BCNFs: (a) BCNF27*/26, (b) BCNF27*1/28 and (c) BCNF27*7/28 for the $1^{\text {st }}, 2^{\text {nd }}, 10^{\text {th }}$ and $50^{\text {th }}$ cycles at $37.2 \mathrm{~mA} \mathrm{~g}^{-1}$. Inset: Magnification of the area below $0.2 \mathrm{~V}$. 

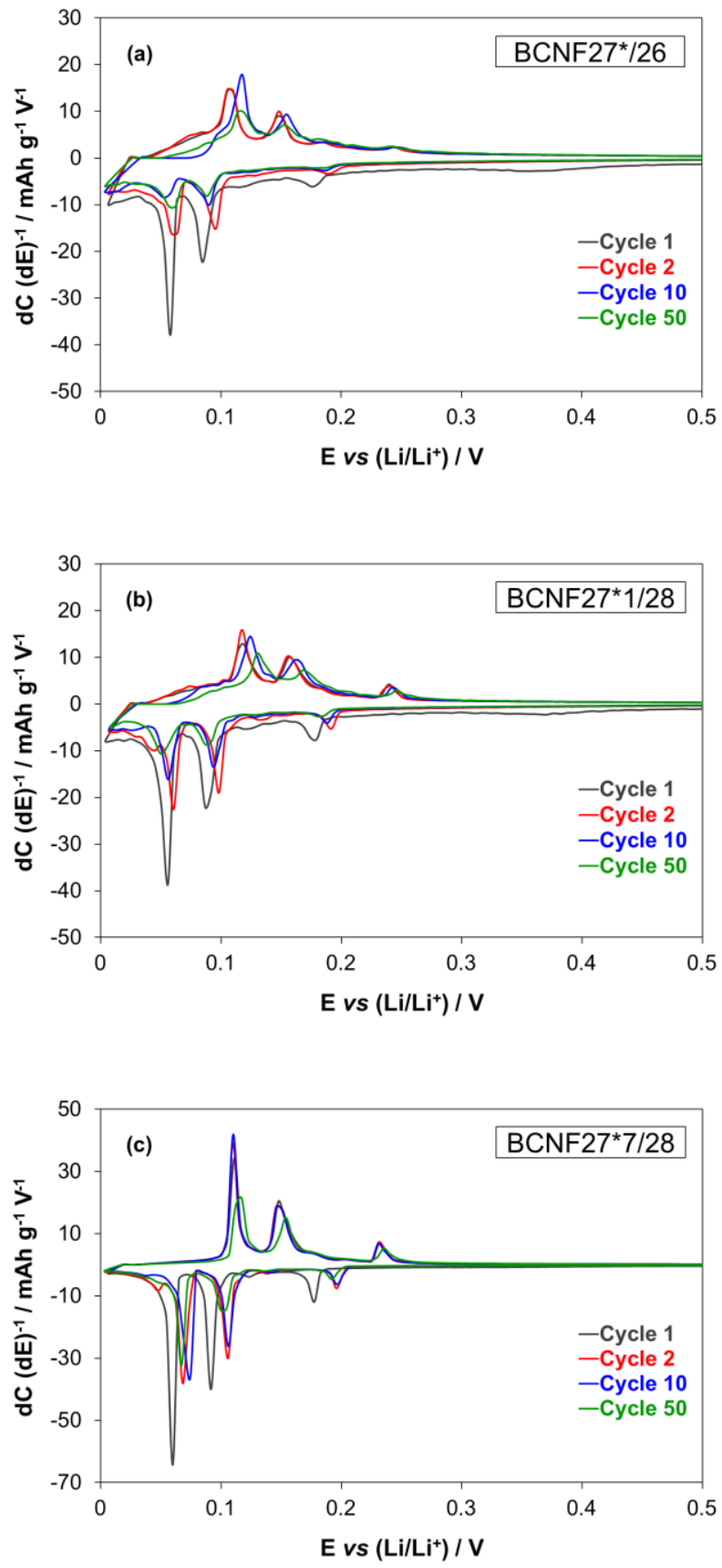

Fig. 2. Differential charge-discharge capacity vs potential plots of graphitized BCNFs: (a) BCNF27*/26, (b) BCNF27*1/28 and (c) BCNF27*7/28 for the $1^{\text {st }}, 2^{\text {nd }}$, $10^{\text {th }}$ and $50^{\text {th }}$ cycles at $37.2 \mathrm{~mA} \mathrm{~g}^{-1}$. 


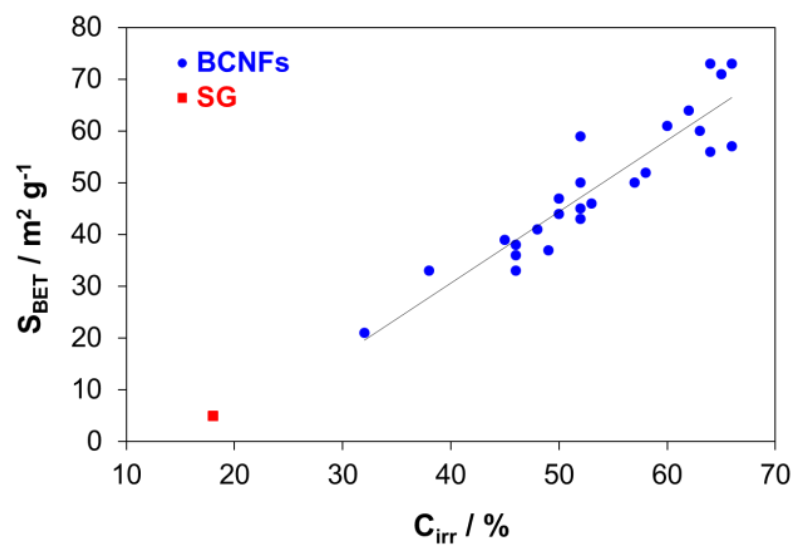

Fig. 3. Surface area, $S_{B E T}$, of the materials vs irreversible capacity, $C_{\text {irr }}(\%)$. 

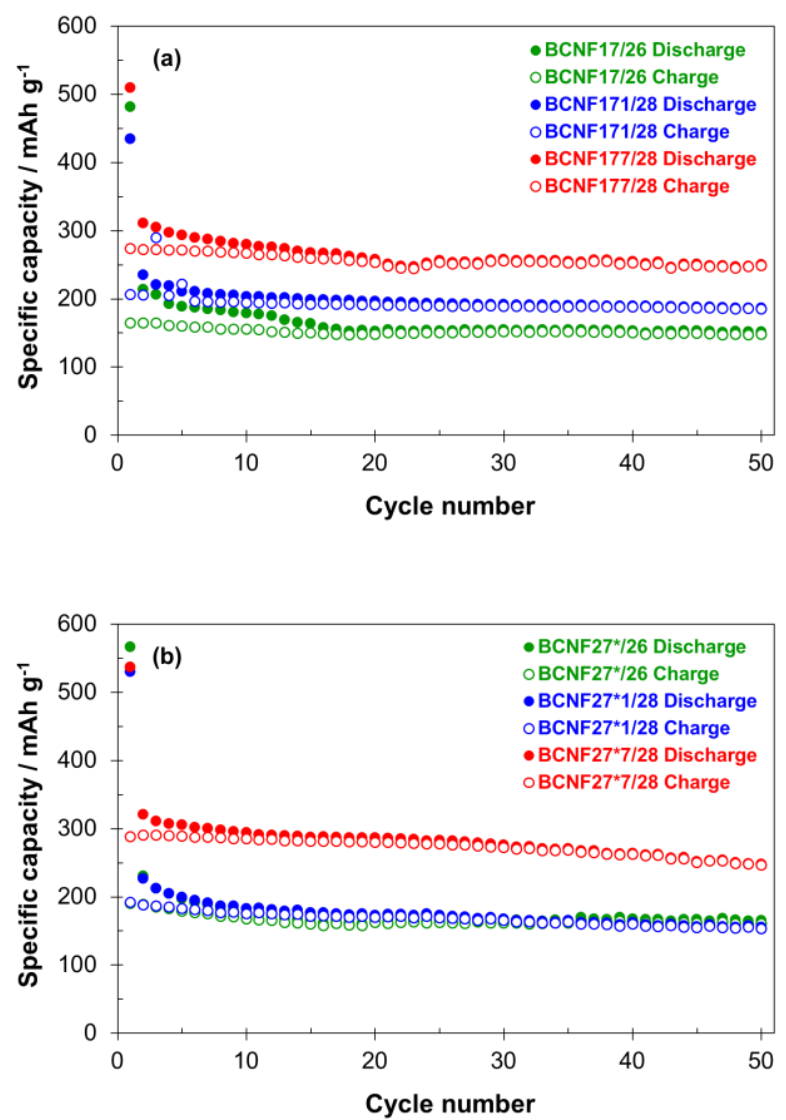

Fig. 4. Galvanostatic cycling at $37.2 \mathrm{~mA} \mathrm{~g}^{-1}$ of two graphitized BNCFs series: (a) BCNF17/26, BCNF171/28, BCNF177/28, and (b) BCNF27*/26, BCNF27*1/28, BCNF277/28. 


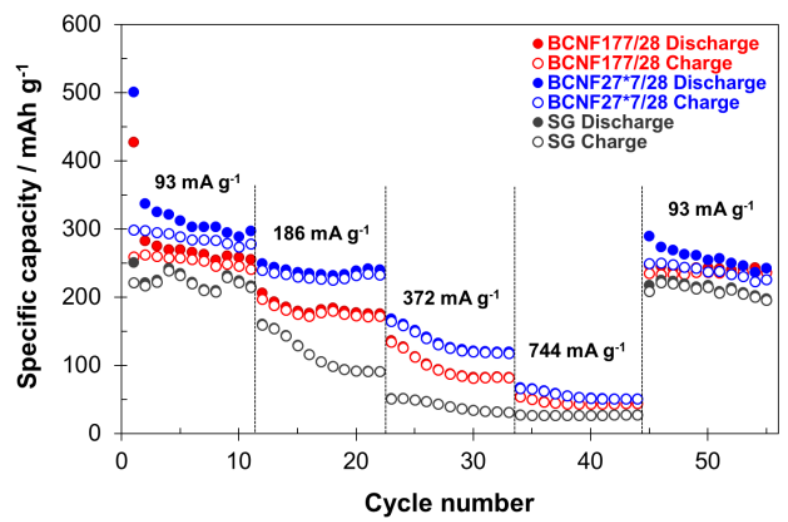

Fig. 5. Cycling performance of $B C N F 177 / 28$ and $B C N F 27^{\star} 7 / 28$ nanomaterials, and SG graphite electrodes at different electrical current densities. 


\section{SUPPORTING INFORMATION}

Table S1. Metal contents of as-produced and as-prepared BCNFs (wt. \%, db).

\begin{tabular}{|c|c|c|c|c|}
\hline BCNFs & $\mathrm{Al}$ & $\mathrm{Ni}$ & Co & $\mathrm{Si}$ \\
\hline $\mathrm{BCNF}^{\mathrm{a}}{ }^{\mathrm{a}}$ & 1.47 & 5.11 & & \\
\hline BCNF161 ${ }^{\mathrm{b}}$ & 1.40 & 4.86 & & 2.31 \\
\hline $\mathrm{BCNF} 165^{\mathrm{b}}$ & 1.17 & 4.05 & & 9.67 \\
\hline BCNF $167^{b}$ & 1.08 & 3.74 & & 12.53 \\
\hline $\mathrm{BCNF} 17^{\mathrm{a}}$ & 2.01 & 6.80 & & \\
\hline $\mathrm{BCNF} 171^{\mathrm{b}}$ & 1.88 & 6.36 & & 3.05 \\
\hline $\mathrm{BCNF} 175^{\mathrm{b}}$ & 1.49 & 5.04 & & 12.07 \\
\hline $\mathrm{BCNF} 177^{\mathrm{b}}$ & 1.35 & 4.57 & & 15.33 \\
\hline $\mathrm{BCNF}^{2} 6^{\mathrm{a}}$ & 1.07 & 3.83 & & \\
\hline BCNF261 ${ }^{b}$ & 1.38 & 3.57 & & 1.71 \\
\hline BCNF265 & 1.20 & 3.11 & & 7.44 \\
\hline BCNF267 & 1.13 & 2.92 & & 9.79 \\
\hline $\mathrm{BCNF} 27^{\mathrm{a}}$ & 1.43 & 3.70 & & \\
\hline BCNF271 & 1.03 & 3.69 & & 1.76 \\
\hline BCNF275 & 0.89 & 3.20 & & 7.66 \\
\hline BCNF277 ${ }^{\mathrm{b}}$ & 0.84 & 3.01 & & 10.06 \\
\hline BCNF27 $7^{\star a}$ & 1.88 & 4.18 & 4.17 & \\
\hline $\mathrm{BCNF} 27^{*} 1^{\mathrm{b}}$ & 1.75 & 3.59 & 3.88 & 3.25 \\
\hline $\mathrm{BCNF} 27^{*} 5^{\mathrm{b}}$ & 1.37 & 3.04 & 3.04 & 12.70 \\
\hline $\mathrm{BCNF} 27^{\star} 7^{\mathrm{b}}$ & 1.23 & 2.75 & 2.74 & 16.04 \\
\hline
\end{tabular}

BCNFs were produced in a rotary-bed reactor by catalytic decomposition of biogas at a space velocity of $30 \mathrm{LN}_{\mathrm{N}} \mathrm{g}_{\mathrm{cat}}^{-1} \mathrm{~h}^{-1}$. Two synthetic biogas mixtures containing only $\mathrm{CH}_{4}$ and $\mathrm{CO}_{2}$ with volume ratios of 50:50 (BG1) and 60:40 (BG2) were used. Experiments were carried out at 600 and $700{ }^{\circ} \mathrm{C}$. Nickel or nickelcobalt catalysts using $\mathrm{Al}_{2} \mathrm{O}_{3}$ as textural promoter with $\mathrm{Ni}: \mathrm{Al}$ or $\mathrm{Ni}+\mathrm{Co}$ :Al molar ratio of 67:33 were prepared by the fusion method. Following biogas designation, the as-produced BCNFs were denoted BCNF1 and BCNF2 together with CDB reaction temperature (6 for $600{ }^{\circ} \mathrm{C}$ or 7 for $700{ }^{\circ} \mathrm{C}$ ), such as BCNF27 for those obtained from a $\mathrm{CH}_{4}: \mathrm{CO}_{2}$ mixture of $60: 40$, at $700 \stackrel{\circ}{\circ} \mathrm{C}$. Moreover, to distinguish between catalysts, an asterisk was added to BCNFs produced with bimetallic NiCo catalyst, i.e. BCNF27 ${ }^{*}$. BCNFs with different Si/metal atomic ratio (1, 5 and 7$)$ were prepared by mixing as-produced BCNFs with powder silica. The resulting asprepared BCNFs were named accordingly by including this atomic ratio. Thus, BCNF271 and BCNF27 ${ }^{*} 1$ are the acronyms for as-prepared BCNFs with $\mathrm{Si} / \mathrm{Ni}$ and $\mathrm{Si} / \mathrm{Ni}+\mathrm{Co}$ atomic ratios of 1 , respectively. 
Figure S1 and Table S2

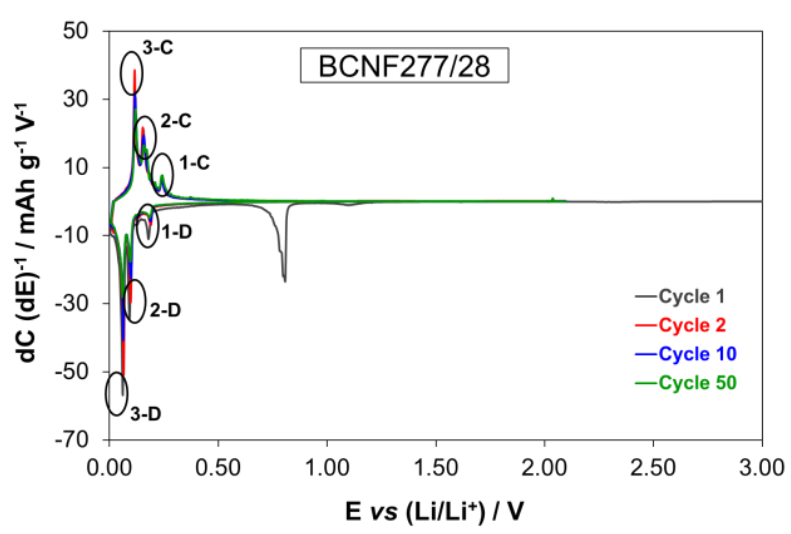

Fig. S1. Differential charge-discharge capacity vs potential plots of BCNF277/28 for the $1^{\text {st }}, 2^{\text {nd }}, 10^{\text {th }}$ and $50^{\text {th }}$ cycles at $37.2 \mathrm{~mA} \mathrm{~g}^{-1}$.

Table S2. Charge/Discharge overpotential ${ }^{\mathrm{a}}(\mathrm{mV})$

\begin{tabular}{l|ccc|ccc|ccc}
\hline \multicolumn{1}{c|}{ Cycle } & \multicolumn{3}{c|}{2} & & \multicolumn{3}{c|}{10} & \multicolumn{3}{c}{50} \\
\hline \multicolumn{1}{c}{ Material } & P 1 & P 2 & P 3 & P 1 & P 2 & P 3 & P 1 & P 2 & P 3 \\
\hline BCNF16/26 & 52 & 52 & 42 & 53 & 53 & 42 & 55 & 60 & 54 \\
BCNF161/28 & 59 & 46 & 35 & 53 & 46 & 46 & 66 & 77 & 61 \\
BCNF167/28 & 48 & 56 & 51 & 48 & 59 & 53 & 56 & 63 & 64 \\
BCNF17/26 & 45 & 50 & 34 & 44 & 52 & 45 & 63 & 62 & 62 \\
BCNF171/28 & 41 & 62 & 56 & 49 & 55 & 49 & 58 & 69 & 56 \\
BCNF177/28 & --- & --- & --- & --- & --- & --- & -- & -- & -- \\
BCNF26/26 & --- & --- & 61 & --- & -- & 66 & -- & -- & 88 \\
BCNF261/28 & 63 & 43 & 59 & 67 & -- & 63 & -- & -- & -- \\
BCNF267/28 & 48 & 58 & 48 & 48 & 60 & 50 & 58 & 64 & 63 \\
BCNF27/26 & 77 & 77 & 64 & 59 & 58 & 52 & 72 & 77 & 67 \\
BCNF271/28 & 64 & 68 & 67 & 71 & 75 & 70 & 66 & 97 & 80 \\
BCNF277/28 & 49 & 55 & 50 & 54 & 59 & 52 & 59 & 59 & 59 \\
BCNF27*/26 & 52 & 52 & 46 & 61 & 64 & 65 & 67 & 64 & 65 \\
BCNF27*1/28 & 51 & 57 & 57 & 54 & 68 & 68 & 66 & 81 & 80 \\
BCNF27*7/28 & 35 & 40 & 42 & 34 & 40 & 36 & 43 & 55 & 50 \\
\hline
\end{tabular}

${ }^{a}$ Overpotential was calculated from Potential P X-C - Potential PX-D

$\mathrm{PX}=$ Peak 1,2 or $3, \mathrm{C}=$ Charge and $\mathrm{D}=$ Discharge . 


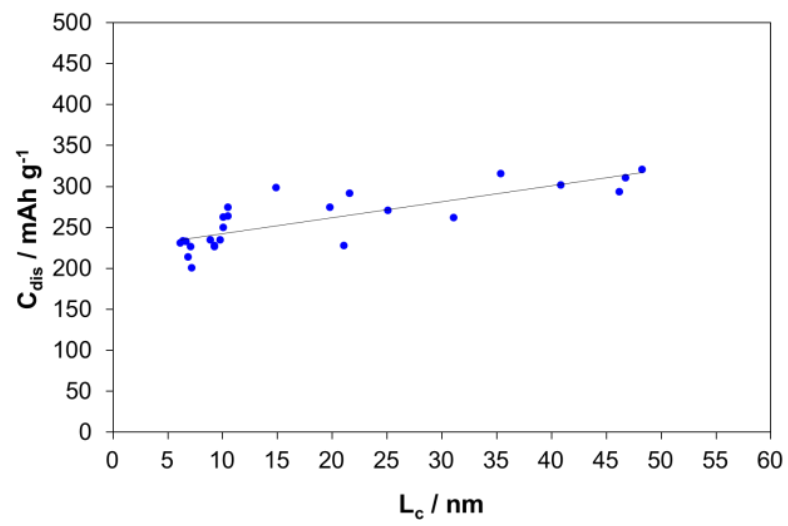

Fig. S2. Discharge capacity at cycle $2 v s$ crystallite size, $L_{c}$, of the graphitized BCNFs (data from Table 1 and 2). 